\title{
AUTHOR INDEX VOLUME 7 (1997)
}

Adam, D., see Wang, N.-L.

Agathoklis, P., see Tawfik, A.

Aguirre, L. A., and Tôrres, L. A. B., Fixed Point Stability Analysis of Chua's Circuit: A Case Study with a Real Circuit

Aissi, C. and Fadul, F., Chaos in Conditionally Reset Linear Systems

Ariyoshi, H., see Takigawa, $\mathrm{K}$.

Babu, N. S. C. and Prasad, V. C., Radial Basis Function Networks for Analog Circuit Fault Isolation

Bass, S. C., see Xu, C. Q.

Bhattacharjee, G. P., see Pal, M.

Bhattacharyya, A., see Janakiraman, P. A.

Cel, J., Tellegen's Theorem for Subnetworks

Chang, M.-F., Irwin, M. J., and Owens, R. M., Power-Area

Trade-Offs in Divided Word Line Memory Arrays

Chen, W.-K., see Tong, M.-D.

Chiba, T., see Okuhata, H.

Ching, P. C., see Wan, K. F.

Choi, B.-T., Lee, K.-H., Ko, S.-J., and Morales, A., Basis Matrix

Representation of Morphological Filters with N-Dimensional Structuring Elements

Choi, J.-H., Kim, B.-T., and Kim, W.-K., Time-Variant Moving

Objects Extraction Using Velocity-Tuned Filter Banks and

Time-Recursion Method in Infrared Image Sequences

Choi, J.-S., see Hong, H.-K.

Chung, J. H., see Lee, W. K.

Chung, J. H., see Yim, Z. K.

Deller, Jr., J. R., see Nayeri, M.

Deng, A.-C., Power Estimation and Power Noise Analysis for CMOS Circuits

Dodds, D. E., see Takaya, N.

El-Guibaly, F., see Tawfik, A.

Er, M. H., see Jian, M.

Fadul, F., see Aissi, C.

Fujita, G., see Miyanohana, K.

Fukui, Y., see Sumi, Y.

Hamada, A., see Takigawa, K.

Han, S.-H., see Hong, H.-K.

Hong, G.-P., see Hong, H.-K.
7 (1997) 1-16

7 (1997) 191-209

7 (1997) 111-115

7 (1997) 177-189

7 (1997) 221-230

7 (1997) 643-655

7 (1997) 563-597

7 (1997) 165-175

7 (1997) 117-127

7 (1997) 641-642

7 (1997) 49-67

7 (1997) 129-151

7 (1997) 483-494

7 (1997) 537-542

7 (1997) 345-352

7 (1997) 283-299

7 (1997) 333-344

7 (1997) 433-440

7 (1997) 419-431

7 (1997) 607-639

7 (1997) 17-30

7 (1997) 273-281

7 (1997) 191-209

6 (1997) 599-606

7 (1997) 177-189

7 (1997) 441-457

7 (1997) 395-405

7 (1997) 221-230

7 (1997) 333-344

7 (1997) 333-344 
Hong, H.-K., Han, S.-H., Hong, G.-P., Jahng, S.-G., and Choi, J.-S., IR Model of 3D Aircraft for Simulation of Reticle Seekers

7 (1997) 333-344

7 (1997) 353-360

Hwangkhunnatham, M., see Leelarasmee, E.

Ikeya, M., Takaki, S., Matsumoto, H., Tani, A., and Komatsu, T., Pulsed Charge Model of Fault Behavior Producing Seismic Electric Signals (SES)

Ioinovici, A., see Zhu, G.

Irwin, M. J., see Chang, M.-F.

Iyer, U., see Nayeri, M.

Jahng, S.-G., see Hong, H.-K.

Janakiraman, P. A., and Bhattacharyya, A., Direct Pole Placement Without Using Observers

Jian, M., Kot, A. C., and Er, M. H., Performance Study of Time Delay Estimation in a Multi-Path Environment

Kawasaki, K., see Takigawa, K.

Kim, B.-T., see Choi, J.-H.

Kim, W.-K., see Choi, J.-H.

Kim, Y.-C. and Lee, H.-S., A Collision-Free Reservation Protocol for WDM Optical Star Networks

Ko, S.-J., see Choi, B.-T.

Komatsu, T., see Ikeya, M.

Koo, G., Lee, G., and Oh, H., MCBP Neural Networks for Efficient Recognition of Tire Classification Code

Kot, A. C., see Jian, M.

Kumatani, K., see Okuhata, $\mathrm{H}$.

Kyung, C.-M., see Yim, J.-S.

Lee, G., see Koo, G.

Lee, H.-S., see Kim, Y.-C.

Lee, K.-H., see Choi, B.-T.

Lee, W. K. and Chung, J. H., Automatic Real-Time Identification of Fingerprint Images Using Wavelets and Gradient of Gaussian

Leelarasmee, E. and Hwangkhunnatham, M., An Implementation of a Matrix Cache to Speed Up the Conventional Transient Simulation of Piecewise Linear Circuit

$\mathrm{Li}$, C. K., see Wan, K. F.

Lim, C. T., see Paik, J. H.

Lin, K.-J. and Wu, C.-W., Practical Realization of Multiple-Input Exclusive-OR Circuits for Low-Power Applications

Liu, M.-S., see Nayeri, M.

Luong, H. C., see Mak, K. C.

Mak, K. C. and Luong, H. C., Performance of a Simple Highly-Linear MOS Analog Mixer

Masaki, T., Nakatani, Y., Onoye, T., and Murakami, K., Voice and Telephony over ATM for Multimedia Network Using Shared VCI Cell

Matsumoto, H., see Ikeya, M.

McCrosky, C. D., see Takaya, N.

Medič, I., see Peršič, B.
7 (1997) 153-164

7 (1997) 69-91

7 (1997) 49-67

7 (1997) 211-219

7 (1997) 333-344

7 (1997) 117-127

7 (1997) 599-606

7 (1997) 221-230

7 (1997) 283-299

7 (1997) 283-299

7 (1997) 459-469

7 (1997) 345-352

7 (1997) 153-164

7 (1997) 361-371

7 (1997) 599-606

7 (1997) 483-494

7 (1997) 301-318

7 (1997) 361-371

7 (1997) 459-469

7 (1997) 345-352

7 (1997) 433-440

7 (1997) 353-360

7 (1997) 537-542

7 (1997) 319-331

7 (1997) 31-48

7 (1997) 607-639

7 (1997) 495-504

7 (1997) 495-504

7 (1997) 93-110

7 (1997) 153-164

7 (1997) 273-281

7 (1997) 407-417 
Miyanohana, K., Fujita, G., Yanagida, K., Onoye, T., and Shirakawa, I., Single Chip Implementation of Encoder-Decoder for Low Bit Rate Visual Communication

Morales, A., see Choi, B.-T.

Murakami, K., see Masaki, T.

Nakatani, Y., see Masaki, T.

Nayeri, M. and Iyer, U., Enhancements to the Adaptive Polyphase Structure

Nayeri, M., Deller, Jr., J. R., and Liu, M.-S., Stochastic Convergence of Optimal Bounding Ellipsoid Algorithms

Newcomb, R. W., see Sellami, L.

Nowrouzian B., see Satyanarayana, J. H.

Obote, S., see Sumi, Y.

Oh, H., see Koo, G.

Ohtsuki, T., see Togawa, N.

Okuhata, H., Uno, H., Kumatani, K., Shirakawa, I., and Chiba, T., A Low Power Receiver Architecture for $4 \mathrm{Mbps}$ Infrared Wireless Communication

Onoye, T., see Masaki, T.

Onoye, T., see Miyanohana, $\mathrm{K}$.

Owens, R. M., see Chang, M.-F.

Paik, J. H. and Lim, C. T., The Analysis of Input Queueing Techniques on a Crosspoint Packet Switch

Pal, M. and Bhattacharjee, G. P., A Data Structure on Interval Graphs and Its Applications

Park, C.-J., see Yim, J.-S.

Park, I.-C., see Yim, J.-S.

Peršič, B. and Medič, I., Extracting Frequency of an Autonomous System by Harmonic Balance

Prasad, V. C., see Babu, N. S. C.

Reinhardt, R. T., see Takaya, K.

Sato, M., see Togawa, N.

Satyanarayana, J. H. and Nowrouzian B., A New Technique for the High-Level Synthesis of Digit-Serial Digital Filters Based on Genetic Algorithms

Sellami, L., Wong, K., and Newcomb, R. W., Semi-State Models for VLSI Hair-Cell Circuits

Shirakawa, I., see Miyanohana, K.

Shirakawa, I., see Okuhata, $\mathrm{H}$.

Shung, C. B., see Tsai, W.-C.

Soliman, A. M., Port Interchange in Voltage Mode Current Conveyor Based Filters

Sumi, Y., Obote, S., Fukui, Y., Tsuda, K., and Syoubu, K., A New Fractional- $N$ PLL Frequency Synthesizer

Syoubu, K., see Sumi, Y.

Tôrres, L. A. B., see Aguirre, L. A.

Takaki, S., see Ikeya, M.

Takaya, K. and Reinhardt, R. T., Low Bit-Rate Image Coding for Facial Movement
7 (1997) 441-457

7 (1997) 345-352

7 (1997) 93-110

7 (1997) 93-110

7 (1997) 211-219

7 (1997) 607-639

7 (1997) 505-516

7 (1997) 517-535

7 (1997) 395-405

7 (1997) 361-371

7 (1997) 373-393

7 (1997) 483-494

7 (1997) 93-110

7 (1997) 441-457

7 (1997) 49-67

7 (1997) 319-331

7 (1997) 165-175

7 (1997) 301-318

7 (1997) 301-318

7 (1997) 407-417

7 (1997) 643-655

7 (1997) 249-259

7 (1997) 373-393

7 (1997) 517-535

7 (1997) 505-516

7 (1997) 441-457

7 (1997) 483-494

7 (1997) 471-482

7 (1997) 543-561

7 (1997) 395 -405

7 (1997) 395-405

7 (1997) 111-115

7 (1997) 153-164

7 (1997) 249-259 
Takaya, K., Recovery of Phase Using Power Spectrum and Bispectrum

7 (1997) 261-272

Takaya, N., Dodds, D. E., and McCrosky, C. D., Adaptive Rate Subscriber Loop Data Transmission Using Ethernet Interfaces

7 (1997) 273-281

Takigawa, K., Hamada, A., Kawasaki, K., and Ariyoshi, H., Analysis of Stability Control of a Power System with a Distributed Constant Circuit Model

7 (1997) 221-230

Tani, A., see Ikeya, M.

Tantaratana, S., Multiplier-Free IIR Filter Realizations with Periodically Time-Varying Coefficients

7 (1997) 153-164

7 (1997) 231-248

Tawfik, A., El-Guibaly, F., and Agathoklis, P., New Realization and Implementation of Fixed-Point IIR Digital Filters

7 (1997) 191-209

Togawa, N., Sato, M., and Ohtsuki, T., A Performance-Oriented Circuit Partitioning Algorithm with Logic-Block Replication for Multi-FPGA Systems

7 (1997) 373-393

Tong, M.-D. and Chen, W.-K., Perfect Multivariable Feedback Theory

Tsai, W.-C. and Shung, C. B., Event-Driven Power Estimation of CMOS Circuits

Tsuda, K., see Sumi, Y.

Uno, H., see Okuhata, $\mathrm{H}$.

Wan, K. F., Ching, P. C., and Li, C. K., A Set of Split-Matrix Ordered Walsh Functions

Wang, N.-L. and Adam, D., Low Power Design for Wireless RF Transceiver - An Industrial View

Wang, X., see $\mathrm{Xu}, \mathrm{C}$. Q.

Wong, K., see Sellami, L.

Wu, C.-W., see Lin, K.-J.

Xu, C. Q., Bass, S. C., and Wang X., Accommodating Linear and Nonlinear Boundary Conditions in Wave Digital Simulations of PDE Systems

Yanagida, K., see Miyanohana, $\mathrm{K}$.

Yim, J.-S., Park, C.-J., Park, I.-C., and Kyung, C.-M., Design Verification of Complex Microprocessors

Yim, Z. K. and Chung, J. H., An Adaptive Motion Estimation Based on the Temporal Subband Analysis

7 (1997) 129-151

7 (1997) 471-482

7 (1997) 395-405

7 (1997) 483-494

7 (1997) 537-542

7 (1997) $1-16$

7 (1997) 563-597

7 (1997) 505-516

7 (1997) $31-48$

7 (1997) 563-597

7 (1997) 441-457

7 (1997) 301-318

7 (1997) 419-431

Zhu, G. and Ioinovici, A., Steady-State Characteristics of Switched-Capacitor Electronic Converters

7 (1997) 69-91 